Actes des congrès de la Société française

\title{
In memoriam Marie-Thérèse Jones-Davies
}

\section{Yves Peyré}

\section{(2) OpenEdition \\ Journals}

Édition électronique

URL : http://journals.openedition.org/shakespeare/1058

DOI : 10.4000/shakespeare.1058

ISSN : 2271-6424

Éditeur

Société Française Shakespeare

Édition imprimée

Date de publication : 1 novembre 2007

Pagination : 247-249

ISBN : 2-9521475-3-1

Référence électronique

Yves Peyré, «In memoriam Marie-Thérèse Jones-Davies », Actes des congrès de la Société française Shakespeare [En ligne], 24 | 2007, mis en ligne le 30 mars 2010, consulté le 21 avril 2019. URL : http:// journals.openedition.org/shakespeare/1058 ; DOI : 10.4000/shakespeare.1058

Ce document a été généré automatiquement le 21 avril 2019

(c) SFS 


\title{
In memoriam Marie-Thérèse Jones- Davies
}

\author{
Yves Peyré
}

1 Ce livre est dédié à la mémoire de Marie-Thérèse Jones-Davies, qui nous a quittés le 26 février, quelques jours avant l'ouverture du congrès 2006 consacré à «Shakespeare poète », auquel elle s'apprêtait à assister.

2 Marie-Thérèse Jones-Davies avait fait partie, avec Henri Fluchère et Jean Fuzier, du groupe fondateur de la Société Française Shakespeare, dont Henri Fluchère fut le premier président. Marie-Thérèse Jones-Davies assurait alors la liaison entre la Société Française Shakespeare et l'International Shakespeare Association, dont elle était membre du bureau exécutif. Elle devint présidente de la Société Française Shakespeare en 1978 et le demeura douze ans, pendant deux mandats, de 1978 à 1984, suivis de deux nouveaux mandats de 1987 à 1993. C'est dire que la Société Française Shakespeare telle que nous la connaissons aujourd'hui est en grande partie son œuvre.

3 Dans ses travaux de recherche, Shakespeare a été constamment présent: Shakespeare et le théâtre du monde obtint en 1987 le prix Biguet de l'Académie Française. Après avoir dirigé l'édition de Hamlet et du Roi Lear aux éditions José Corti, elle travaillait encore, tout récemment, aux volumes consacrés aux pièces historiques pour l'édition Pléiade des CEuvres de Shakespeare, dirigée par Jean-Michel Déprats.

4 En même temps, elle a inlassablement œuvré pour faire connaître en France les contemporains de Shakespeare. Consacrée à Thomas Dekker, sa thèse principale, qui obtint en 1958 la médaille de bronze du CNRS et le prix Albéric Rocheron de l'Académie Française, figure parmi les ouvrages de référence qui aidèrent les historiens français à comprendre la société anglaise de la Renaissance. Elle fut suivie par la traduction et l'édition du Chevalier de l'ardent pilon, par le beau livre Inigo Jones, Ben Jonson et le masque, par un ouvrage consacré à Ben Jonson, qui en est à sa seconde édition, et par la solide synthèse de Victimes et rebelles, l'écrivain dans la société élisabéthaine. Ces travaux la destinaient tout naturellement à participer activement au Théâtre élisabéthain dirigé par François Laroque pour la collection de la Pléiade. 
5 Sa connaissance approfondie de la littérature et de la société élisabéthaines était indissociable de son intérêt pour les littératures européennes de la Renaissance. C'est pourquoi elle avait fondé la Société Internationale de Recherches Interdisciplinaires sur la Renaissance, qu'elle a dirigée pendant trente ans. Le trentième colloque, qu'elle préparait au moment de son décès, était consacré au silence au temps de la Renaissance.

6 Cette œuvre immense, toute de précision, de lucidité et de générosité, a été accomplie dans un contexte universitaire dont on sait qu'il n'est pas toujours favorable aux études élisabéthaines. Mais Marie-Thérèse Jones-Davies a constamment fait front, avec le courage et la détermination qui la caractérisaient. Le courage et la détermination avec lesquels, au début de sa carrière, elle avait fui l'occupation pour rejoindre les troupes alliées; le courage et la détermination avec lesquels, alors qu'elle ne se déplaçait plus qu'avec difficulté, pour ne pas faillir à un engagement professionnel, elle avait pris l'avion pour Venise en portant ses affaires dans un sac à dos afin de pouvoir s'appuyer sur deux canes; le courage et la détermination avec lesquels, jusqu'au bout, elle a tenu tête à la maladie.

7 À l'annonce de son décès, j'ai reçu de nombreux témoignages de l'affection et du respect que lui portaient collègues et amis. Tous rappellent avec émotion sa disponibilité, sa capacité d'écoute, son dévouement et sa bonté. À ces témoignages spontanés, qu'il me soit permis d'ajouter le mien. À l'occasion d'un colloque organisé dans le sud de l'Angleterre, Marie-Thérèse Jones-Davies avait désiré faire une incursion jusqu'à Yarmouth pour y voir les endroits où avait vécu Thomas Nashe. Je lui objectai que la ville avait été presque entièrement détruite par les bombardements de la dernière guerre, puis reconstruite, et qu'il n'était guère probable qu'y ait survécu quelque vestige du seizième siècle. Elle ne voulut rien entendre, si vive était en elle cette flamme du chercheur qui pousse à tout vérifier par soi-même. Nous allâmes donc à Yarmouth, pour constater qu'il n'y restait effectivement plus aucune trace du séjour de Nashe. Au retour, après avoir médité sur la fragilité des choses humaines, et s'être interrogée sur la mort, elle dit, en accompagnant ses paroles d'une ferme insistance de son regard clair, qui trahissait aussi une pointe d'inquiétude, elle dit ces mots qui l'expriment en entier : « Il faudra continuer .» Puisse la Société Française Shakespeare continuer son œuvre, non seulement pour que son souvenir demeure vivace en nous, mais pour qu'il nous guide aussi comme un exemple. 